\title{
One Important Lesson I've Learned from My Involvement with SoTL
}

\section{ABSTRACT}

As a regular feature in Teaching \& Learning Inquiry, we will ask leading thinkers in the field of SoTL to articulate one important lesson they have learned over the course of their careers. In this first installment, Joy Mighty talks about leadership in its numerous forms, from individual to institutional, and its potential for the development of SoTL. Before becoming the Associate Vice-President, Teaching and Learning, at Carleton University in Ottawa, Joy was the Director of the Centre for Teaching and Learning and Professor in the School of Business at Queen's University in Canada. Joy has also served as the President of the Society for Teaching and Learning in Higher Education, and is the co-editor of Taking Stock: Research on Teaching and Learning in Higher Education.

\section{KEYWORDS}

Developing SoTL, Educational Development and SoTL, Leadership of SoTL

I have been directly involved in the Scholarship of Teaching and Learning (SoTL) in various capacities over the years, but this reflection on one important lesson learned stems from my role as an educational developer seeking for many years to encourage others' involvement in SoTL.

The contexts in which I have operated have been very similar to other contexts across the country where the prevailing culture of research-intensive institutions values and supports the scholarship of discovery in the disciplines above all other forms of scholarship. For example, reward structures and other systems supporting the scholarship of discovery abound and exceed by a considerable degree supporting infrastructure for the scholarships of integration, application, and teaching. Annual performance review processes emphasize traditional research output paradigms such as publications in "top-tiered" journals and the acquisition of competitive internal and external research grants. By contrast, SoTL is often perceived in such contexts as the individual pursuit of some personal interest rather than "real" research, and the existing dominant belief typically is that those who cannot succeed in disciplinary research teach or resort to SoTL.

I recall writing a letter to an internal research grant committee on behalf of a faculty member whose application for a grant to support his legitimate SoTL work was rejected because, according to the committee, such research grants were not meant to support an individual's 'hobby.' My letter, an appeal of sorts, included an exposition on SoTL and 
a justification for regarding it as legitimate scholarship. The response to my letter was kind but firm. In essence, it said: we are sorry, but the type of activity described in your letter is not appropriate for this particular grant; perhaps the faculty member should try elsewhere. Unfortunately, there was no alternative internal grant for which the faculty member could apply for support of his SoTL. In one institution, there was, until two years ago, a marked absence of an institution-wide teaching and learning strategy. Not surprisingly, there were few internal monetary or other incentives in support of SoTL and external recognition from the wider SoTL community was typically undervalued. In this context, the self-imposed, gargantuan goal of building a strong SoTL community seemed a near impossibility.

However, despite the ongoing challenges of engaging in educational development activities in such contexts, in due course I identified several forces in support of incremental change towards wider acceptance of SoTL. For one thing, I recognized the importance of creating numerous opportunities for SoTL scholars to interact with each other to offset the isolation they often felt from doing SoTL in the seemingly unsupportive institutional contexts described earlier. Fostering SoTL appeared to be more achievable within scholarly communities. Thus, my fellow educational developers and I actively encouraged the development of such communities across our institution. The basis of the scholarly community did not seem to matter. What did matter was that participants perceived that they could share ideas, methodologies, experiences, or results on common topics related to their SoTL activities.

Over time, there developed a diverse range of scholarly communities: institutional, disciplinary, pedagogical, internal, external, structural, or strategic. These functioned in different ways, with different degrees of autonomy. For example, one scholarly community was focused on assessment of learning. The members self-identified based on their declared interest in the subject, and they convened their own meetings with a frequency and regularity unmatched by any other scholarly community. Another was primarily interested in exploring together various writing processes for disseminating their SoTL. This community was more dependent on us, as educational developers, to schedule meetings and provide a structure for them. Indeed, when we no longer took the lead in creating opportunities for this particular scholarly community to meet on a regular basis, the community disintegrated. On reflection, this brings me to what is perhaps the most important lesson that I have learned in relation to SoTL — the critical role of leadership.

I view leadership as the capacity to influence others to work towards a set of shared goals. That capacity often resides in positions of authority, such as deans and heads of departments whose positions in the organizational structure officially give them the power to influence their faculty to act in particular ways. Whether they choose to exercise that power is another matter altogether, but the potential for influence exists. Thus, I have seen department heads and deans establish small grants for which faculty members engaged in SoTL have successfully applied. Similarly, some deans and heads who understand and value SoTL have given appropriate recognition and credit for such work to faculty members in their annual performance reviews. One dean even established a SoTL award in his faculty. Exercising leadership in this way may have significant consequences beyond the deserving recognition of individuals engaged in SoTL. One such consequence is the message such leadership signals to the department, school or faculty as a whole that SoTL is valued and will be rewarded. Another consequence is the motivation it arouses in others. 
However, formal position is not the only source of leadership for fostering SoTL. Leadership may also be informal and may emerge from some of the most unlikely sources. For example, in one institution, efforts to engage students and promote deep, active learning led to the establishment of a university-wide, inquiry-based initiative where undergraduate students were encouraged, but not mandated, to participate in research activities typically associated with graduate students. As the initiative developed, students sought out faculty members as informal mentors or coaches in their research projects and, over time, several of these faculty members began to ask their own questions about the impact of such unusual, un-prescribed research activity on students' learning. Several SoTL projects (and a scholarly community on the subject) subsequently emerged. These were projects that might never have come to fruition without the unintended influence or leadership of highly motivated students.

Similarly, the importance of leadership among peers cannot be underestimated when it comes to promoting SoTL, particularly in research-intensive institutions. Many of us are familiar with the kinds of stories and legends that are often passed on to new or junior faculty members about what they need to do to succeed in our institution's promotion and tenure process. Chief among such stories is the age-old adage to "publish or perish." New faculty members are often advised by their more senior colleagues to focus on their research and their teaching will take care of itself. The message is clear: disciplinary research or research of discovery outweighs all other types of scholarship as the way to earn tenure and promotion. However, I have found that the presence in a faculty or department of a few SoTL advocates or champions could go a far way in offsetting the SoTL naysayers and restoring the balance among different types of scholarship, as Boyer urged us to do so many years ago. Such advocates and champions often do not have positional power, but what they do have is the capacity to influence by their example. I can think of several individuals, from various disciplines, who have revealed during consultations with me in my capacity as an educational developer that they have been inspired by their colleagues' passion for and success in SoTL. Sometimes, they may openly connect with their advocates or champions, seeking assistance or opportunities to collaborate or simply share experiences. But I have also seen clandestine (professional) liaisons between novice and expert SoTL actors in contexts where openly expressing one's interest in SoTL could adversely affect junior faculty members' opportunities for career advancement.

Perhaps one of the most significant sources of leadership for the promotion of SoTL is the disciplinary association. When associations take the lead in accepting for their conferences and journals submissions with a SoTL focus, or having a division or stream dedicated to SoTL in the discipline, they exercise strong influence on the future direction and growth of SoTL. Not only do they provide opportunities for making SoTL public, one of the distinguishing characteristics of SoTL, perhaps more importantly, they send a very powerful message about the relevance and importance of SoTL in their discipline. Involvement in their disciplinary association is often one of the most highly respected and valued pieces of evidence of an academic's accomplishments and most individuals are influenced to pursue the types of activities that their association values. This reality underscores the importance of the disciplinary association's leadership in fostering SoTL.

A final example of the important lesson that I have learned from my involvement with SoTL is the necessity for institutional leadership which may be manifested in many forms. The most obvious manifestation of an institution's commitment to SoTL lies in 
its strategic plan which is the document that articulates the institution's vision and mission. What an institution's strategic plan explicitly states about its recognition and value of SoTL will ultimately have implications for whether faculty choose to pursue SoTL and for the expectations and subsequent behaviour of students who choose the institution. Moreover, the strategic plan typically gives rise to a host of other plans, including the academic plan. It is here that specific objectives and activities for implementing the strategic plan are clarified. How an institution involves its various departments, faculties and individuals in implementing its plans could make all the difference in whether SoTL becomes an enduring value within that institution's culture. This is where the role of the educational development unit becomes especially important. How such a unit is structured and resourced becomes a critical indicator of the institution's commitment to SoTL.

By the same token, how the educational development unit chooses to exercise its leadership potential could significantly influence the SoTL movement within the institution. For example, such a unit should be able to establish and administer the kinds of teaching and learning research grants that are appropriate for SoTL work, especially in the absence of such grants elsewhere in the institution (as in my earlier letter of appeal example). The educational development unit should provide opportunities for SoTL work to be made public within its various activities such as workshops, symposia, showcases, and scholarly communities. In addition, it should encourage diversity within SoTL, ensuring that such work is not perceived as relevant or valuable only in certain disciplines, or that only certain activities constitute legitimate SoTL. In short, I have learned that, while there are many sources of leadership influencing SoTL within an institution, the educational development unit has the ultimate responsibility to demonstrate its own committed, inspirational leadership by harnessing the other sources and ensuring integration of the multiple institutional SoTL pathways. The educational development unit's leadership role is to ensure that there is a clearly articulated vision for SoTL and that there is alignment of policies, structures, programs, partnerships, advocates and champions, incentives and rewards, all leading to the enhancement of teaching and learning through SoTL.

Joy Mighty serves as the Associate Vice-President, Teaching and Learning, at Carleton University in Ottawa. 